\title{
O Papel do Tutor na Humanização da Aprendizagem
} na Educação a Distância

\section{The Role of the Tutor in the Humanization of Learning in Distance Education}

\section{Simone Guimarães Custódio* \\ Márcia Maria Dias Reis Pacheco \\ Camila Aparecida Silva Rosa \\ Marinelo \\ Laís Renó Stábile Costa \\ Giovanna Velloso dos Santos \\ Universidade de Taubaté. \\ Rua Visconde do Rio Branco, 210 \\ Taubaté - SP - Brasil. \\ *edcristasimone@gmail.com}

\section{Resumo}

A Educação a Distância cumpre uma exigência da globalização trazendo o acesso ao conhecimento de maneira mais rápida e eficiente. Nessa modalidade, a internet torna-se cada vez mais uma fonte de informações pluricultural de alcance comunitário. No entanto, uma das dificuldades nessa metodologia de ensino parece ser a ausência de acompanhamento pedagógico eficiente. Compreender como deve acontecer a tutoria, quais as características do profissional que atua nessa modalidade pode tornar esse processo de ensino-aprendizagem mais significativo. Este artigo investiga $\mathrm{a}(\mathrm{s})$ maneira(s) adequada(s) como esse processo de acompanhamento deve ser desenvolvido para que o aluno obtenha sucesso no processo de aprendizagem no ensino a distância. Buscou-se identificar os agentes facilitadores na aquisição do conhecimento com qualidade segundo os autores Jean Piaget e Lev Vygotsky e, com base nos pressupostos teóricos de Behar (2009) a respeito do modelo pedagógico em EaD, delineou-se o perfil e a preparação acadêmico-pedagógica necessária aos profissionais dessa área, a fim de que possam colaborar efetivamente com o desenvolvimento do educando nesse processo. A metodologia constitui-se de pesquisa bibliográfica.

Palavras-chave: Educação a distância. Tutoria presencial. Qualidade de ensino. Acompanhamento. 


\section{The Role of the Tutor in the Humanization of Learning in Distance Education}

\section{Abstract}

Distance education fulfills a requirement of globalization by bringing access to knowledge faster and more efficiently. In this mode, the Internet is increasingly becoming a source of pluricultural information with community reach. However, one of the difficulties in this teaching methodology seems to be the absence of efficient pedagogical monitoring. Understanding how tutoring should happen and what are the characteristics of the tutor can make this teaching and learning process more meaningful. This article investigates the appropriate way(s) that the monitoring process should be developed to achieve student success when learning at a distance. There is an attempt to identify the agents that facilitate the acquisition of knowledge with quality according to the authors Jean Piaget and Lev Vygotsky and based on Behar's (2009) theoretical assumptions about the pedagogical model in Distance Education, the tutor's academic profile and training was outlined - needed by professionals in this area to effectively collaborate with the development of the student in this process. The methodology consists of bibliographic research.

Keywords: Distance education. Tutoring. Quality of teaching. Monitoring.

\section{Introdução}

A história da Educação a Distância se confunde com a história da revolução tecnológica. Para Battes (2016) e Castells (1999), o campo educacional foi e ainda é muito beneficiado pela criação e pelo desenvolvimento dos recursos tecnológicos.

Moran (2009) indica que a EaD acontece em três momentos caracterizados pela inovação ou criação de recursos tecnológicos que, segundo a definição de Mattar (2014), não trata apenas de equipamentos eletrônicos, mas de qualquer recurso que possibilite a transmissão de conhecimento e que possa acontecer independente do tempo e do espaço, pois permite ao conhecimento ser "armazenado" e "transportado".

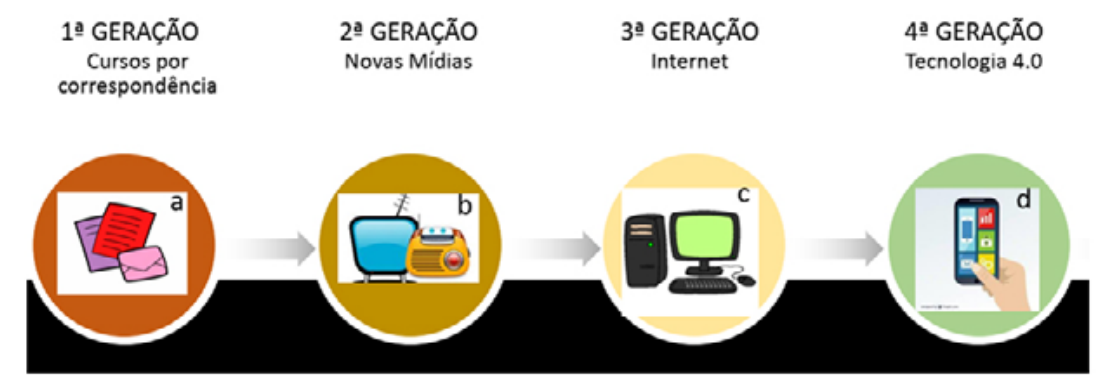

Figura 1: Gerações da Educação a Distância Fonte: Moran (2009); Schwab (2016).

Esses momentos se dividem em quatro gerações, conforme demonstra a Figura 1: (1) a geração dos cursos por correspondência e material impresso; (2) a geração das novas mídias (rádio, TV, fitas de áudio e vídeo); (3) a geração da internet (videotexto, microcomputador, tecnologia de multimídia, hipertexto e 
redes de computadores, caracterizando a EaD on-line); e (4) geração 4.0 (caracterizada pela incorporação de tecnologias da inteligência artificial, da robótica, da internet das coisas, dos veículos autônomos, da impressão em 3D, da nanotecnologia, da biotecnologia, do armazenamento de energia, dos dispositivos "vestíveis" (wearable), da edição de genes, da inteligência de máquinas e dispositivos eletrônicos em rede) (MORAN, 2009; SCHWAB, 2018).

A cultura cibernética chegou ao Brasil juntamente como as tecnologias digitais de informação e comunicação (TDIC); após a regulamentação inicial, promove grande expansão de cursos em nível de graduação e até mesmo de pós-graduação que acontecem na modalidade de Educação a Distância.

De acordo com o censo da educação superior divulgado pelo Instituto Nacional de Estudos e Pesquisas Educacionais Anísio Teixeira (INEP) em 2017, mais de dois mil cursos foram reconhecidos pelo Ministério da Educação (MEC). O total de vagas oferecidas chegou a mais de quatro milhões em instituições de ensino superior públicas e privadas em todo o Brasil. Dessas vagas ofertadas, cerca de $42 \%$ foram preenchidos, totalizando cerca de 1,7 milhão de matrículas.

Ainda de acordo com dados do censo, existem mais de sete mil polos de instituições públicas e privadas que se encontram regulamentados pelo MEC para a oferta de cursos de graduação em Educação a Distância (INEP, 2017).

De fato, essa é uma modalidade que cresce significativamente a cada ano e revela um novo cenário no campo educacional, marcado pela força dos processos de globalização pautados pela evolução da tecnologia trazendo nova concepção pedagógica caracterizada pela tendência progressiva que se constitui na flexibilização extrema e na individualização da força de trabalho. Esse novo momento tem sido de transformação dos paradigmas sociais, que, segundo Patrícia Behar, "já não estão mais dando conta das relações, das necessidades e dos desafios sociais" (BEHAR, 2009, p. 15).

Essa nova estrutura social segmentada rompe com a ideia de uma sociedade que centraliza seus esforços de ensino-aprendizagem apenas no conhecimento técnico direcionado para a força de trabalho e traz a cultura da aprendizagem voltada para uma sociedade em rede que privilegia a construção do conhecimento por meio da mediação (BEHAR, 2009; CASTELLS, 1999). Nesse contexto de mudança de comportamento e paradigmas encontra-se a Educação a Distância, que se caracteriza por quatro aspectos principais: a "distância" propriamente dita; o uso dos recursos tecnológicos; a cultura da autoaprendizagem e o modelo pedagógico de construção de conhecimento por meio da mediação.

Não se concebe mais uma estrutura social sem o uso das TDIC para praticamente todos os aspectos da vida social e pessoal. O campo educacional é mais uma área que está envolvida nessa nova tendência. O modelo de Educação a Distância com a utilização das TDIC chegou para ficar. No entanto, não está nessa discussão a utilização dos recursos tecnológicos para fins de formação educacional; antes, porém, como esse novo modelo pedagógico pode de fato produzir com eficiência uma formação de qualidade, de maneira que os profissionais que optam por estudar a distância possam ter êxito em sua prática profissional? Esta é uma modalidade que, essencialmente, utiliza as tecnologias; no entanto, essa discussão se cria sob o aspecto de como essa cultura da autoaprendizagem pode se tornar eficiente e quais elementos são necessários para que isso aconteça.

Apesar da grande oferta e expansão, ao se propor o desenvolvimento de um projeto em EaD é necessário que haja uma série de ações que envolvem diversos aspectos, desde a estrutura física, administrativa, tecnológica até ações didático-pedagógicas mais específicas.

A EaD transforma o "ser aluno" e o "ser professor" não apenas no aspecto físico ou em relação ao tempo, mas nos processos de aprendizagem e interação. Nesse tipo de formação, além da interação entre os sujeitos - aluno-professor e aluno-aluno - é necessário o estímulo às relações e interações aluno-informação, 
aluno-tecnologia, professor-informação, professor-tecnologia e entre professor-professor, uma vez que esses diferentes tipos de interação em conjunto possibilitam que a construção do conhecimento se torne colaborativa.

Essa é uma discussão importante no que se refere principalmente às ações dos interlocutores desse processo, levando em conta as suas características, pois são os principais responsáveis pelo êxito ou insucesso dessa proposta.

Para entender esse novo cenário e seus "atores", é preciso analisá-lo com base na interação entre duas tendências relativamente autônomas: a tentativa da antiga sociedade de aparelhar-se com o uso do poder da tecnologia para servir a tecnologia do poder e o desenvolvimento de novas tecnologias da informação, que atualiza a metodologia, aprimora a didática e insere o aluno no mundo digital de fato (CASTELLS, 1999).

É preciso atentar-se para a qualidade dessa educação que está sendo disseminada pela informatização. Ela precisa ser estruturada adequadamente a esse público que por muito tempo ficou sem acesso a todo esse conhecimento. Por isso a discussão a respeito da importância do fator humano e da necessidade ou não dos encontros presenciais nesse processo de construção e aquisição do conhecimento torna-se relevante, como acentua Azevedo,

\begin{abstract}
o acesso facilitado à informação não garante melhor aprendizagem. As tecnologias da informação e de comunicação, se não forem utilizadas em um contexto pedagógico renovado, inovador e criativo e com intervenções pontuais dos tutores, poderão apenas reproduzir o modelo de ensino presencial tradicional, sem que haja aproveitamento das diversas possibilidades que essas ferramentas poderiam proporcionar ao professor (AZEVEDO, 2014, p. 11).
\end{abstract}

Assim, propomos neste artigo uma análise do novo papel do professor (ou tutor, como tem sido chamado) nessa modalidade de ensino. Também discorremos sobre as ações da tutoria que podem favorecer a prática pedagógica eficiente, bem como as características que esse novo "profissional" deve possuir e quais as melhores maneiras de executar esse trabalho de maneira que possa cumprir o objetivo educacional proposto.

Como exercer a mediação sem perder o foco na qualidade? Que fatores podem contribuir para que o ensino a distância mantenha o mesmo índice de qualidade de um curso presencial?

Para responder a essas questões, investigaram-se três aspectos principais da formação docente em EaD, que são: (1) os fundamentos pedagógicos da EaD e a descrição desse novo modelo pedagógico; (2) o processo de ensino-aprendizagem dos alunos em questão, conhecendo os fundamentos pedagógicos a partir da abordagem sociointeracionista de Lev Vygotsky; e (3) com base nessa teoria, identificaram-se as características e a formação necessárias para a atuação do profissional. Nesse último aspecto, investigouse como a tutoria deve ser exercida a fim de promover a aprendizagem por meio da Educação a Distância, mesmo que o tutor não esteja fisicamente próximo ao educando.

\title{
2. Processo de Ensino-Aprendizagem na Educação a Distância
}

Compreender os fundamentos do processo ensino-aprendizagem é fundamental para que se entenda e construa a melhor didática para o ensino a distância. A primeira abordagem, mais conhecida pelos educadores, fala do construtivismo, em que o conhecimento é concebido e construído, segundo Piaget, 
por assimilação e acomodação, ou seja, quando o aluno é colocado diante de algo desconhecido, ocorre o processo que chamamos de assimilação, em que o indivíduo incorpora a informação e os conhecimentos preexistentes são alterados. Quando o novo conhecimento é assimilado e aceito pelo indivíduo, passa por um novo processo, que é o de acomodação (equilíbrio), em que se torna um conceito.

Lev Vygotsky (1984) ajuda a compreender os fundamentos do processo ensino-aprendizagem, fator fundamental para entender e construir a melhor didática para o ensino a distância. Para ele, em sua abordagem sociointeracionista, a aprendizagem acontece como um fenômeno que se realiza na interação com o outro, ela deflagra vários processos internos de desenvolvimento mental que tomam corpo somente quando o sujeito interage com objetos e sujeitos em cooperação. Uma vez internalizados, esses processos tornam-se parte das aquisições do desenvolvimento. O aluno aprende observando o meio, entrando em contato com o que já foi descoberto e organizando o conhecimento com os outros (professor e turma). O papel do professor nesse processo é de orientador ou "mediador" do conhecimento. Esse é o fator humano imprescindível para que o aprendizado aconteça de fato.

As ações desenvolvidas no âmbito dos cursos a distância possibilitam repensar a organização do espaço da ação educativa e devem ter por objetivo assegurar a promoção do ser humano, minimizando os efeitos marginalizadores, excludentes, seletivos e impessoais do sistema educacional tradicional. Assim, em qualquer processo de ensino-aprendizagem, quer seja presencial ou a distância, o papel do professor é causar o desequilíbrio no aluno, agindo como mediador entre ele e o conhecimento. A Educação a Distância deve propiciar essa interação de maneira adequada para que o discente seja desafiado a construir o seu conhecimento.

Para que isso aconteça, o tutor precisa estar inserido nesse cenário como referência e motor de mudança e inovação para os seus alunos. Ele deve ter preparação acadêmico-pedagógica para lidar com todos os aspectos dessa formação.

Outra questão importante que se deve considerar ao refletir sobre a Educação a Distância é a explicação e a regulação do processo de intervenção pedagógica nessa modalidade, que se baseia nos sistemas de comunicação didática entre os docentes, tutores e estudantes por meio do diálogo, habitualmente mediado, seja simulado, real, sincronizado ou assíncrono (AZEVEDO, 2014, p. 8).

Conforme Azevedo (2014), torna-se imprescindível que o professor da EaD conheça as técnicas, estratégias e modelos de investigação educativa para que possa se tornar um tutor eficiente com resultados positivos.

\section{Um Novo Modelo Pedagógico}

As primeiras experiências de Educação a Distância consideraram a primeira tendência apontada por Manuel Castells (1999), que se refere ao reaparelhar-se dos recursos tecnológicos para o serviço do poder político e foram questionadas em relação à qualidade do ensino praticado e se tornou ponto de discussão importante tanto no âmbito coletivo como individual, pois, apesar de ter mudado a nomenclatura, essas primeiras práticas em EaD repetiam o modelo pedagógico tradicional apenas alternando ou acrescentando o uso de recursos tecnológicos.

As discussões aconteceram e ainda hoje são pauta de diversos eventos relacionados à Educação, pois ainda se questiona a qualidade do profissional que se forma nessa modalidade em virtude do projeto pedagógico mal estruturado, em que não há reconsideração sobre o uso dos recursos tecnológicos em 
função de uma nova concepção de aprendizagem, quando eles deveriam facilitar a comunicação, mediação ou interação pedagógica, assumindo o caráter de construção de conhecimento.

O modelo pedagógico em EaD deve ater-se às estratégias pedagógicas para essa modalidade em que se tenha em mente o objetivo de buscar o desenvolvimento de habilidades e competências a fim de possibilitar ao professor o desenvolvimento de sua identidade profissional sólida, por meio de simulações e práticas do saber fazer docente. Para Gatti (2014), há que se repensar as estruturas desse formato de ensino, especialmente para os cursos de licenciatura. Para ela,

a necessidade de suportes fortes aos estudantes em cursos a distância requer cuidados especiais, e o custo de um projeto bem formatado, qualificado e consistente é alto. [...] Essa modalidade, rica em possibilidades, a despeito das críticas que lhe são devidas, requer alternativas que contribuam para fortalecê-la e consolidá-la. Para tanto, os caminhos atuais têm que ser alterados (GATTI, 2014, p. 34).

Seja no modelo semipresencial, em que parte da carga horária é apresentada em encontros presenciais semanais ou mensais, seja no modelo totalmente a distância, em que o aluno não precisa estar na instituição, exceto para a realização das avaliações, momento que é obrigatório de acordo com o Decreto n 5.622 , de 19 de fevereiro de 2005, a atuação dos professores assume nova composição, transformando a relação aluno-professor ao acentuar sua ação para os aspectos de mediação. Nesse novo papel, o agora chamado tutor virtual ou presencial rompe com a "velha" concepção de que o professor é o "detentor" do conhecimento, inserindo uma nova roupagem, a de mediador que direciona o aluno ao conhecimento. Para isso, realiza tanto orientações on-line como aulas expositivas, em temas específicos ou complementares às atividades que são realizadas na plataforma virtual, que são realizadas presencialmente ou gravadas e disponibilizadas posteriormente por meio digital.

O aluno também já não é mais o mesmo. Deixou de ter papel "passivo", em que só assistia às aulas e realizava as atividades. Para Lobato, o aluno é um ser ativo nesse processo:

O discente - no contexto mundial - não pode se resumir a um ser passivo, que escuta, lê e repete os ensinamentos do professor. O que se espera, pelo contrário, é que a tal aprendiz sejam propostos métodos para torná-lo crítico, atuante e pesquisador de maneira que, assim, o mesmo esteja apto a produzir "conhecimento". Evidentemente, considera-se que, a partir daí, o indivíduo poderá torna-se um profissional autônomo e criativo que, com competência, tenha (dentre várias outras habilidades) a capacidade de solucionar problemas, apontar caminhos para os mesmos e, ainda, lutar por mudanças e por um mundo com melhores condições de sobrevivência (LOBATO, 2009, p. 3).

Nesse novo modelo de educação, principalmente quando o aluno opta pela realização do curso de maneira totalmente a distância ou on-line, a sua atuação é acrescida da responsabilidade de organizar seus horários de estudo, acessar o material de maneira digital e organizar sua rotina de leituras e realização de atividades. Isso demanda organização pessoal, disciplina e comprometimento. 


\section{Formação Acadêmica do Tutor e as Características da Tutoria}

Uma tutoria desenvolvida com qualidade é muito importante para que o aprendizado se concretize. A figura do tutor é aquela do professor orientador que tem a responsabilidade não só de ensinar, mas principalmente de motivar e apontar o caminho da pesquisa e aquisição do conhecimento.

Esse é o profissional que faz a aproximação do aluno com o conteúdo e ampara o processo de ensino-aprendizagem, dando suporte para que ele possa construir o próprio conhecimento. Para Vergara, o professor ou o tutor têm a responsabilidade de desafiar e orientar o aluno em relação à aquisição de conhecimento em cada aula que se passa.

Do ponto de vista acadêmico, a responsabilidade principal [...] do tutor é provocar e orientar os alunos para o maior ganho educacional possível; [...] o papel do tutor é de extrema relevância nesse processo. A presteza nas respostas ao aluno é fundamental, ele acompanha e monitora atividades sincrônicas, como os chats, web TVs e gincanas, e as assincrônicas, como os fóruns de discussão. Tutores devem ter a capacidade de provocar nos alunos a vontade consciente de compartilhamento de reflexões e compreensões e a ação neste sentido e, dessa forma, instigar a construção do conhecimento coletivo. Devem, ainda, provocar no aluno a compreensão de que se ele não faz leitura prévia, se não realiza estudo individual e trabalhos em grupo, perde espaço nos chats. Afinal, a EaD exige autodisciplina, liberdade acompanhada da responsabilidade. É de relevância estar atento a alunos que "desaparecem". É preciso monitorar, chamá-los, incentivá-los a prosseguir. Demonstrar que se preocupa com ele (VERGARA, 2007, p. 6).

É importante que os tutores sejam profissionais formados na área específica da disciplina em que atuam, pois é fundamental que sejam críticos o suficiente para realizar autoavaliação, ou seja, se estão cumprindo todas as necessidades atreladas à tutoria, sejam elas relacionadas ao curso, à disciplina em que atuam ou ao aluno.

É importante ressaltar que a formação para atuação a distância é indicada como fator de excelência, porém não obrigatória, conforme o Decreto n 5.622 .

Art. 12. O pedido de credenciamento da instituição deverá ser formalizado junto ao órgão responsável, mediante o cumprimento dos seguintes requisitos: [...]

VIII - Apresentar corpo docente com as qualificações exigidas na legislação em vigor e, preferencialmente, com formação para o trabalho com educação a distância (Decreto $n^{\circ}$ 5.622, de 19 de fevereiro de 2005, artigo 12, item VIII).

A formação teórica específica é parte muito importante da formação; porém, para que haja construção completa, a contextualização ou visualização prática se torna imprescindível. Ela não deve diferir daquela que qualquer profissional voltado à Educação precisa contemplar. Ela deve ser ampla, com a especialização do curso em que irá atuar ou com a formação de licenciatura plena em Pedagogia, para que ele possa ter condições de acompanhar todo o processo de ensino-aprendizagem, seja na produção de materiais, interação das aulas, acompanhamento de atividades ou o processo avaliativo. 


\title{
5. Desafio da Interação
}

Um dos desafios da interação na Educação a Distância se dá por causa dos elementos de tempo e o espaço. Para Daiana Trein (2008), a EaD, por causa desses elementos, possibilita a existência de um currículo não linear, favorece o surgimento de um modelo de mediação pedagógica configurado pela interação sujeito-sujeito e sujeito-meio. Esse novo modelo desfaz os referenciais tradicionais, em que "o professor é o detentor do saber e o aluno um mero espectador com a função de 'absorver' o conhecimento" (TREIN, 2008, p. 7).

Para Trein (2008), as concepções de professor e aluno modificam-se, tornando o aluno não mais o sujeito que apenas absorve o conteúdo, mas que interage com o objeto de estudo na busca de informações, construindo assim a sua autonomia, tornando-se sujeito da própria educação. É preciso repensar todas as metodologias, os conceitos e as formas de ser e agir como professor.

\begin{abstract}
Para dar conta das novas necessidades que surgem com a EaD, o professor necessita buscar o diálogo com seus alunos, com o currículo, com a informação e consigo mesmo. Repensar as práticas significa buscar na sua ontogenia as respostas para as novas necessidades, refletir sobre o ser aluno e o ser professor, na cultura do ensino e na cultura da aprendizagem (TREIN, 2008, p. 16).
\end{abstract}

Deve-se levar em conta o fator distância, que não existe no ensino tradicional ou presencial e que surge na EaD. Os sujeitos não estão habituados com a interação e isso pode tornar-se um fator de dificuldade para o êxito dos alunos. A "distância" física na EaD transforma o ser aluno e o ser professor. Não necessariamente apenas no aspecto físico ou em relação ao tempo, mas nos processos de interação em si.

A tutoria, seja feita em encontros pontuais (encontrados no modelo semipresencial) ou apenas virtuais, é extremamente necessária para que a mediação pedagógica ou interação vá além da comunicação teórica do professor com o aluno, pois ela os aproxima num diálogo físico que tem o intuito de construir, criar e atingir um mesmo objetivo: a aprendizagem.

Trein afirma ainda que "o professor, mais do que ter fluência tecnológica, precisa desejar, sentir prazer e estar aberto ao novo, ao inesperado, ao que não foi programado" (TREIN, 2008, p. 20). E esse é o grande desafio do tutor, pois a interação é essencial para que a aprendizagem e a mediação pedagógica na EaD tenham significado.

Trein (2008) diz também que "a interação é natural do ser humano, as descobertas só se tornam significativas quando realizadas por meio da ação e da reflexão sobre a ação" (TREIN, 2008, p. 22). Moraes (2003) concorda quando afirma que, além da interação entre os sujeitos - aluno-professor e aluno-aluno -, a tutoria presencia e estimula as relações e interações aluno-informação, aluno-tecnologia, professor -informação, professor-tecnologia e professor-professor, uma vez que esses diferentes tipos de interação em conjunto possibilitam a construção do conhecimento de forma a se tornar colaborativa.

\section{Qualidade em Educação e a Preparação Acadêmico-Pedagógica do Tutor}

Discutir a qualidade em Educação é, sem dúvida, adentrar um campo amplo e de concepções diversas; porém, para essa discussão consideramos as definições de Demo (2001) que a analisa em três aspectos: acadêmica, social e educativa. 
Quadro 1: Descrição da qualidade em educação

\begin{tabular}{|l|l|l|}
\hline \multicolumn{1}{|c|}{ Acadêmica } & \multicolumn{1}{|c|}{ Social } & \multicolumn{1}{c|}{ Educativa } \\
\hline $\begin{array}{l}\text { Aquela que surge na } \\
\text { produção original do } \\
\text { conhecimento por meio } \\
\text { da docência e refere-se às } \\
\text { capacidades do professor de } \\
\text { transmitir conhecimentos } \\
\begin{array}{l}\text { advindos das práticas de } \\
\text { pesquisa que convergem em } \\
\text { soluções para problemas } \\
\text { específicos da sociedade. }\end{array}\end{array}$ & $\begin{array}{l}\text { Aquela que provém das ativi- } \\
\text { dades de ensino, de pesquisa } \\
\text { e de extensão, as instituições } \\
\text { educacionais atuam de forma } \\
\text { relevante no desenvolvimen- } \\
\text { to da sociedade. }\end{array}$ & $\begin{array}{l}\text { Aquela que consegue atingir } \\
\text { o nível de construção ou } \\
\text { formação da cidadania de } \\
\text { maneira que este possa } \\
\text { inferir e interferir na sua } \\
\text { realidade social. }\end{array}$ \\
\hline
\end{tabular}

Fonte: Demo (2001).

O professor que pretende atuar como tutor de EaD deve vivenciar um processo de formação "em" EaD que possibilite a aquisição de conhecimentos fundamentais para o desempenho dessa função. Esse processo deve promover o conhecimento e o desenvolvimento da própria autonomia e da autoria do sujeito, atitudes de colaboração/cooperação e parceria entre os sujeitos.

A mediação pedagógica pautada na perspectiva socioconstrutivista apresentada por Vygotsky compreende a construção do conhecimento como processo dinâmico e relacional, em que o tutor possui papel fundamental que direciona suas ações e a individualização de atendimento acadêmico que oferece apoio aos alunos para que possam ter condiç̃̃es de utilizar os materiais disponíveis, facilitando e motivando as situações de aprendizagem.

O tutor deve ter claro o perfil acadêmico que deve levar em conta as suas habilidades e competências, assim como suas condições socioculturais (familiar, profissional, social) e assim apresentar uma didática pedagógica menos diretiva. $\mathrm{O}$ aluno tem em si já certa autonomia; normalmente está na fase adulta e é capaz de encontrar em si mesmo as motivações e as necessidades para aprender e fazer opções sobre o modo como desenvolverá seu próprio processo de educação.

Perrenoud (2000, p. 139) fala do papel do tutor em ambiente de ensino virtual e diz que "mais do que ensinar, trata-se de fazer aprender, concentrando-se na criação, na gestão e na regulação das situações de aprendizagem".

É importante considerar que o tutor é um professor, um educador, e não apenas um "tirador de dúvidas"; um formador de múltiplos conhecimentos. Para isso, ele deve, além de tirar as dúvidas, elaborar atividades que facilitem o estudo, usar diferentes meios para se comunicar com os alunos e atender de modo atencioso e cordial os discentes.

As competências centram-se nas quatro grandes áreas de conhecimento: pedagógicas, socioafetivas, tecnológicas e as competências gerenciais. O Quadro 2 apresenta as principais características de cada uma dessas quatro áreas. 
Quadro 2: Principais competências do professor tutor em EaD

\begin{tabular}{|c|c|c|c|}
\hline Pedagógicas & Socioafetivas & Tecnológicas & Gerenciais \\
\hline $\begin{array}{l}\text { Domínio do conteúdo, } \\
\text { do idioma nacional } \\
\text { falado e escrito. }\end{array}$ & $\begin{array}{l}\text { Cordialidade na recep- } \\
\text { ção e no atendimento } \\
\text { de informações e } \\
\text { dúvidas. }\end{array}$ & $\begin{array}{l}\text { Conhecimento e práti- } \\
\text { ca da informática. }\end{array}$ & $\begin{array}{l}\text { Concepção da aprendi- } \\
\text { zagem humana como } \\
\text { troca de experiências } \\
\text { entre pessoas }\end{array}$ \\
\hline $\begin{array}{l}\text { Identificação do perfil } \\
\text { dos alunos e o con- } \\
\text { texto em que eles se } \\
\text { situam, de modo a } \\
\text { identificar suas neces- } \\
\text { sidades e adaptar-se } \\
\text { a elas. }\end{array}$ & $\begin{array}{l}\text { Aceitação - na com- } \\
\text { preensão da realidade } \\
\text { do aluno, suas dificul- } \\
\text { dades e facilidades de } \\
\text { aprendizagem. }\end{array}$ & $\begin{array}{l}\text { Produção de textos, } \\
\text { arquivos e gráficos. }\end{array}$ & $\begin{array}{l}\text { Comunicabilidade; } \\
\text { organização, instrução } \\
\text { dos discentes sobre os } \\
\text { procedimentos básicos } \\
\text { do curso e esclare- } \\
\text { cer dúvidas sobre o } \\
\text { material destinado aos } \\
\text { alunos. }\end{array}$ \\
\hline $\begin{array}{l}\text { Apreciação do sistema } \\
\text { de avaliação do curso e } \\
\text { da disciplina. }\end{array}$ & $\begin{array}{l}\text { Honradez - ser ver- } \\
\text { dadeiro, autêntico e } \\
\text { atencioso. }\end{array}$ & $\begin{array}{l}\text { Domínio de diferentes } \\
\text { mídias e das tecnolo- } \\
\text { gias digitais de infor- } \\
\text { mação e comunicação } \\
\text { (TDIC). }\end{array}$ & $\begin{array}{l}\text { Iniciativa para oferecer } \\
\text { respostas rápidas. }\end{array}$ \\
\hline $\begin{array}{l}\text { Conhecimento da } \\
\text { proposta pedagógica } \\
\text { do curso. }\end{array}$ & $\begin{array}{l}\text { Ter respeito à diversi- } \\
\text { dade cultural. }\end{array}$ & $\begin{array}{l}\text { Utilizar com proprie- } \\
\text { dade as tecnologias da } \\
\text { informação e comuni- } \\
\text { cação disponibilizadas } \\
\text { no ambiente virtual. }\end{array}$ & \\
\hline $\begin{array}{l}\text { Planejamento e avalia- } \\
\text { ção pedagógica. }\end{array}$ & $\begin{array}{l}\text { Empatia - saber se } \\
\text { colocar no lugar do } \\
\text { outro. }\end{array}$ & $\begin{array}{l}\text { Incentivar a partici- } \\
\text { pação individual e } \\
\text { coletiva por meio de } \\
\text { mensagens. }\end{array}$ & $\begin{array}{l}\text { Facilidade para sugerir } \\
\text { revisões, interpre- } \\
\text { tações alternativas, } \\
\text { indicar aprofunda- } \\
\text { mentos e para fazer } \\
\text { comentários que levem } \\
\text { ao aprimoramento de } \\
\text { competências profis- } \\
\text { sionais. }\end{array}$ \\
\hline $\begin{array}{l}\text { Clareza na expressão } \\
\text { verbal (oral ou escrita). }\end{array}$ & & $\begin{array}{l}\text { Mediar conflitos e } \\
\text { promover a interação e } \\
\text { a colaboração entre os } \\
\text { discentes. }\end{array}$ & $\begin{array}{l}\text { Facilidade para elogiar } \\
\text { e reforçar interpre- } \\
\text { tações inovadoras e } \\
\text { alcances dos alunos. }\end{array}$ \\
\hline $\begin{array}{l}\text { Avaliar trabalhos, } \\
\text { provas e a participação } \\
\text { dos alunos. }\end{array}$ & & $\begin{array}{l}\text { Ter domínio das ferra- } \\
\text { mentas tecnológicas } \\
\text { comunicacionais e } \\
\text { informacionais. }\end{array}$ & $\begin{array}{l}\text { Intermediar as discus- } \\
\text { sões entre os alunos; } \\
\text { valorizando as contri- } \\
\text { buições dos discentes; } \\
\text { fazer o encaminha- } \\
\text { mento de questiona- } \\
\text { mentos devidos ao } \\
\text { suporte técnico. }\end{array}$ \\
\hline
\end{tabular}

Fonte: Aretio e Veras, apud Giannella (2007); Preti apud Ramos (2008).

\section{Conclusão}

Como observamos, cada vez mais o número de alunos que procuram cursos que se realizam pela Educação a Distância tem crescido, e a oferta pelas instituições de ensino também. É necessário, entretanto, que se observe a qualidade dessa oferta, estruturando de maneira adequada o material didático (desenvolvendo com base nos fundamentos pedagógicos adequados), a tutoria (com a formação de professor orientador), o ambiente e os recursos tecnológicos (atualizados). 
O conhecimento só se revela na prática profissional. Se quisermos conferir se a educação está sendo desenvolvida de maneira adequada, observem-se os alunos em sua área de atuação. Com um ensino estruturado, temos como resultado a qualificação profissional que dá frutos no mercado de trabalho, que por sua vez produz maior busca dessa forma de ensino.

A prática docente na modalidade a distância e/ou semipresencial pressupõe mudanças. Um aspecto destacado por esta pesquisa diz respeito à distância afetiva que a inserção de recursos tecnológicos traz para a prática docente.

Elementos novos são incorporados ao processo de aprendizagem e de construção do conhecimento; os professores atuam como tutores, e essa é uma prática de natureza bilateral em que os alunos e tutores se conectam na rede de conhecimento; a característica principal desse relacionamento é a colaboração e a orientação. A interação deve ser preservada; portanto - seja de maneira virtual, por qualquer rede de comunicação ou nos encontros presenciais -, o grande desafio é manter a humanização nas ações, falas e transmissão de conhecimento.

A linguagem, a empatia, a tonalidade da fala e a atenção são características do professor que podem ser transmitidas presencial ou virtualmente. E são essas características que tornam o estudar motivador.

Há que se ressaltar a riqueza que existe nas trocas de experiência, seja por meio dos fóruns ou das orientações síncronas que podem acontecer em tempo real, com possibilidade de mudança de pensamento movida pelas expressões de sentimentos dos relatos.

Diante disso, concluímos que os recursos tecnológicos são parte importante para que a EaD aconteça, mas fundamentalmente, para se constituir um modelo pedagógico eficiente, é necessário observar o elemento humano e suas particularidades que definem as relações que poderão resultar em ações profissionais de qualidade.

As instituições de ensino superior devem se preocupar com a formação integral do tutor e sua valorização, pois este uma vez atuando de maneira adequada, pode fazer com que os alunos tenham uma boa formação que os capacite a participar de diferentes experiências nas várias atividades, enriquecendo sua formação acadêmica e oferecendo possibilidades de se tornar um profissional humanitário consciente de seu valor, direitos e deveres.

Portanto, estudar a Educação a Distância é continuar refletindo sobre a necessidade de conciliar a mudança de paradigma de uma sociedade tradicional para a sociedade da informação, que se torna cada dia mais aparelhada de recursos tecnológicos, mesmo nas suas camadas mais simples, com os pressupostos da formação docente, a fim de que se chegue a uma estrutura adequada que considere a tecnologia e a educação para o benefício e crescimento do país.

\section{Referências Bibliográficas}

Alves, C.M.T. Metodologias para a Educação a Distância. Valinhos: Anhanguera Educacional, 2013. Disponível em: <http://anhanguera.com>. Acesso em: 1 mar. 2014.

ALVES, C.M.T.; SOLEDADE, R.T. Elaboração de conteúdo em EaD. Valinhos, 2013. Disponível em: <http://anhanguera.com>. Acesso em: 1 mar. 2014.

AZEVEDO, A.B. Tutoria em EaD. Valinhos: Anhanguera Educacional, 2014. p. 1-68. Disponível em: < $\underline{\text { http:// }}$ anhanguera.com>. Acesso em: 03 fev. 2014. 
BATES, A.W.T. Educar na era digital: design, ensino e aprendizagem. Trad. João Mattar et al. São Paulo: Artesanato Educacional, 2016.

BRASIL, DECRETO N 5.622, de 19 de dezembro de 2005. Regulamenta o art. 80 da Lei n 9.394, de 20 de dezembro de 1996, que estabelece as diretrizes e bases da educação nacional. Disponível em https:// www2.camara.leg.br/legin/fed/decret/2005/decreto-5622-19-dezembro-2005-539654-publicacaooriginal-39018-pe.html

BEHAR, P.A. Modelos pedagógicos em EaD. Porto Alegre: Artmed, 2009.

CASTELLS, M. A sociedade em rede. Atualização para a 6a edição: Jussara Simões (A era da informação: economia, sociedade e cultura, v. 1). Trad. Roneide Venâncio Majer. São Paulo: Paz e Terra, 1999.

DEMO, P. Educação e qualidade. 6a ed. São Paulo: Papirus, 2001.

FERREIRA, A.B.H. Minidicionário da língua portuguesa. 3ª ed. Rio de Janeiro: Nova Fronteira, 1993.

GIANNELLA, T. R.; STRUCHINER, M.; RICCIARDI, R.M.V. Lições aprendidas em experiências de tutoria a distância: fatores potencializadores e limitantes. Laboratório de Tecnologias Cognitivas - Nutes/UFRJ. Educação Pública, Rio de Janeiro. Disponível em: <http://www.educacaopublica.rj.gov.br/biblioteca/ educacao/0059.html>. Acesso em: 02 jan. 2014.

INEP. O Instituto. 2003. Disponível em <http://portal.inep.gov.br/sinopses-estatisticas>. Acesso em: 18 jul. 2017.

JODAS, J. Polo de apoio presencial. Valinhos: Anhanguera Educacional, 2014. Disponível em: < http:// anhanguera.com>. Acesso em: 30 ago. 2014.

LOBATO, I.M. O processo interativo na educação a distância: professor, aluno e material didático. Revista Paidéi@, v. 2, n. 1, jun. 2009. Disponível em: <http://revistapaideia.unimesvirtual.com.br/index.php?journal=pai- deia\&page>. Acesso em: 13 fev. 2014.

LOPES, M.M.F. A competência gerencial do tutor em um curso a distância. Artigo apresentado no XVIII Encontro Latino-Americano de Iniciação Científica, XIV Encontro Latino-Americano de Pós-Graduação e IV Encontro de Iniciação à Docência - Universidade do Vale do Paraíba, novembro de 2014.

MENEZES, E.T. de; SANTOS, T.H. dos. "Mediação pedagógica" (verbete). Dicionário Interativo da Educação Brasileira. EducaBrasil. São Paulo: Midiamix, 2012. Disponível em: <http://www.educabrasil.com. br/eb/dic/dicionario.asp?id=44>.

MORAES, M.C. Educar na biologia do amor e da solidariedade. Petrópolis: Vozes, 2003.

PERRENOUD, P. Dez novas competências para ensinar: convite à viagem. Porto Alegre: Artmed, 2000.

RAMOS, M.S. Qualidade da tutoria e a formação do tutor: Os efeitos desses aspectos em cursos a distância. UNIREDE. 2013. Disponível em: <http://www.aedi.ufpa.br/esud/trabalhos/poster/AT1/112988. pdf>. Acesso em: 19 set. 2013.

TREIN, D. Formação docente em e para EaD. Universidade do Vale do Rio dos Sinos - UNISINOS. Jul. 2008. Disponível em: http://www.abed.org.br/congresso2008/tc/512200893710PM.pdf.

VERGARA, S.C. Estreitando relacionamentos na educação a distância. Cad. Ebape. BR, Rio de Janeiro, v. 5, nº Especial, jan. 2007. Disponível em: <http://www.scielo.br/scielo.php?pid=S167939512007000500010\&script=sci>. Acesso em: 20 dez. 2014.

VYGOTSKY, L.S. A formação social da mente: o desenvolvimento dos processos psicológicos superiores. São Paulo: Martins Fontes, 2007. 